\title{
1. Setting the stage for transport in human scale cities
}

\author{
Miloš N. Mladenović, Karst T. Geurs, Elias \\ Willberg and Tuuli Toivonen
}

By far the greatest and most admirable form of wisdom is that needed to plan and beautify cities and human communities. (Attributed to Socrates)

\section{THE NEED FOR MOBILITY SYSTEM TRANSFORMATION TOWARDS A HUMAN SCALE}

Millennia have passed since the above statement attributed to Socrates of Athens. One can only imagine that Socrates had something in mind for posterity with that statement. Nonetheless, one could wonder what can Socrates teach us in the 21 st century. After all, are not the problems of Athens rather minute to us, as we now collectively as humanity face a range of wicked challenges? Was not Athens rather an exception of its time, since the majority of the population did not live in cities, as opposed to our rapidly urbanizing planet at the moment? Nowadays, we recognize our existence in a state of deep uncertainty, for all our cities. Such a deep uncertainty became widely apparent with the worldwide COVID-19 pandemic. During this time, it has become even more obvious how crucial a role transport systems have for the functioning of our urban communities.

Besides the important role for functioning of 21 st century cities, the transport sector is still one of our greatest sustainability challenges (Geurs and Macharis, 2019). The 21st century is the century when we need to radically reduce our dependence on fossil fuels and thus reduce the amount of greenhouse gas emissions. This includes a significant reduction in carbon emissions from urban transport, which are not declining at an acceptable rate (IPCC, 2019). Of course, transport is contributing not only to greenhouse gas emissions, but also to a range of other environmental pollutants, affecting a range of aspects, from our bodies to cultural soundscapes. At the same time, energy and other resources are limited, just as is our planet (Raworth, 2012), and we have to adapt to the ongoing changes of our planet (Koetse and Rietveld, 
2012). In addition, transport is the eighth-leading cause of death globally, with 1.35 million deaths and 50 million injuries each year (WHO, 2018). Hand in hand with direct safety and security issues, our urban mobility systems have contributed to further deterioration of our physical and mental health, locking us further into inactive lifestyles and depleting our social capital (Lucas et al., 2016).

All in all, we have a long list of challenges ahead for our automobility regime (Urry, 2004). However, the challenge is not solely that we experience these and many other undesired consequences. In addition, the challenge is not only that aggregate negative effects are significant, but also that mobility is so intertwined with the functioning of our society that any initiative aimed at either increasing or reducing it inevitably leads to both positive and negative effects - making it a true moral dilemma (Bertolini, 2017). Thus, our challenge is one of not only utilitarian but also distributive justice. Observed through this perspective of distributive justice (Rawls, 1971), we now know that many of these harmful consequences are not equally distributed across diverse humans in our cities. We all too often find that certain groups of people bear the greatest burden, including for example children, the elderly, poor, LGBTQ (lesbian, gay, bisexual, transgender, queer or questioning), or persons of colour.

In general, we know what should be done to transform our currently unsustainable urban mobility systems. First and foremost, we need to reduce the total amount of travelling and make a rapid modal shift away from car-dependent lifestyles supported by systemic efficiency increases (Banister, 2008). However, the devil in the details still lurks, if we are to change our future lifestyles. We have to face the fact that our urban mobility systems are irreducibly complex, with non-linear and rapidly changing dynamics due to a large number of interdependent natural and infrastructural relations (de Roo and Silva, 2010). Thus, systemic transformation requires a necessary trade-off by ensuring fairness during and from this transition, and delivering well-being and quality of life for all; making this transition essentially an intra- and intergenerational social justice question (Sheller, 2018). Such transitions out of our unsustainable lifestyles require changes not only in the built environment, technological systems or even policies but also, most importantly, in our behaviours and societal values (Geels et al., 2017).

\section{A HUMAN BEING ON THE MOVE IN THE HUMAN SCALE CITY}

If we are to talk about changes in human behaviour, values and ultimately lifestyles, we ought to ask ourselves: what is it to be a human on the move in the city? The human in the city imagined after World War Two (WW2), during the foundational stage of transport engineering as a discipline, is Homo 
economicus. Travelling for that human is a burden and derived demand, as demand for a factor of production or intermediate good that occurs as a result of the demand for another intermediate or final good. Such a human is able to calculate the generalized cost of each journey as the risk- and comfort-adjusted weighted sum of time spent on travel or activity, the associated expenditure and the social content of the movements and activities. Such a human is essentially a utility maximizer, capable of perfectly understanding and ranking all alternatives, with stable preferences over time, and living in a world with little to no externalities. The rational decision made by such a human is to minimize transport costs, often expressed as quantity of travel time.

This simplified image of a human being has combined well with civil engineering and operations research disciplines gaining importance after experiences during WW2, and the strengthening of research-based universities. At the core of their epistemology, these disciplines, in line with neoclassical economics, focus on an aggregated, and some would say narrow utilitarian, perspective on mobility systems. Thus, understanding complex mobility systems needs primarily aggregated spatio-temporal representations, such as average annual daily traffic or origin-destination desire lines. Moreover, understanding mobility system dynamics requires only understanding relations between quantifiable parameters of traffic volume, density, speed and travel time. Conveniently, such aggregations fit well with the supply and demand curves used to represent system equilibrium in neoclassical economics. As a result, taking actions in regard to mobility systems is seemingly impossible to not be formulated as a straightforward objective function, such as minimizing total travel time of all the users on a given network.

Contrary to the Homo economicus model, there is a large body of evidence developed after WW2 that everyday travel decisions are not exclusively governed by perfectly evaluating, cost-minimizing and utility-maximizing human beings. Our rationality is not as comprehensive as the Homo economicus model would suggest, but it is ultimately bounded (Simon, 1990), as we rely on mental shortcuts and heuristics, with plenty of decision biases. We are at the same time driven by risk aversion, seeking stability and routine on the one hand; while often seeking variety, as desire for the unfamiliar or even alteration between familiar alternatives, on the other hand. We often simplify everyday decisions to a manageable level using these heuristics, as long as they keep on working without a critical failure of the decision-making process. These rules of thumb about everyday mobility decisions, such as choices of modes or routes, are coloured with different affective and cognitive experiences (De Vos, 2019), whose effect over time helps them to be formed and reformed. These individual experiential considerations are vital for the overall happiness and wellbeing, and can in turn have far-reaching implications on social and environmental issues (Nasar, 1988). In addition, urban mobility systems are 
determined by our collective customs and assigned meanings of normality, and in relation to these have an important role to play in creating stability and reliability needed for everyday mobility practices (Cairns et al., 2014). Finally, such norm-based underpinnings of our mobility behaviour might be framed by both positive freedom, as opportunity to act, and negative freedom, as permission to act without constraints (Berlin, 1969 [2000]).

In addition to the above examples, at the centre of much-needed reinterpretation of the human being on the move in the city is that human ends are multidimensional, but are also not static and fully defined, with changes within a single individual and over various groups, all over time. In addition, one of the key knowledge turns is that humans are in their everyday essence moving beings: Homo mobilis (Mladenović et al., 2019; Van Geenhuizen and Nijkamp, 2003). To get a glimpse at further layers in our understanding beyond Homo economicus, one only needs to think about the greatest punishment we impose in the modern legal systems, which is significant restriction of movement in prisons; or the difficulty of citizens across the globe to comply with travel restrictions imposed by governments to cope with COVID-19 pandemic. Thus, Homo mobilis often has an intrinsic desire to move in the everyday environment, with travelling being an endemic fact of daily flow that can be a purposive activity in itself (Jensen, 2009). With these examples, our intention is certainly not to end the story of Homo mobilis, or to pretend to have a unified grand theory of human beings. Nonetheless, we would underline the need to move away from the imagined Homo economicus, no matter whether on the surface such a model presents us with an apparent unity in understanding the human being.

\section{TOWARDS TRANSFORMING OUR UNDERSTANDING OF FUTURE-MAKING ORGANIZATIONS}

The 20th century paradigm of Homo economicus, aggregation as the way to understand system dynamics, and straightforward objective functions focused all too often on minimizing, is now in turmoil. Perhaps it is not only inevitable that the paradigm will gradually decline and fade away. Perhaps it is bound to disappear into history by rapid and sudden collapse. Perhaps this disadvantageous paradigm just needs the final nudge to collapse. With the above-mentioned fundamental gap in our understanding about mobile humans in the city, was there after all some wisdom in Socrates mentioning the greatest and most admirable form of 'wisdom' needed for shaping these living environments? It seems that we need to continue our reflection further. What deeper challenges for the paradigm shift and adaptation of the institutional capacity can we identify beyond the usually mentioned resource constraints, or often-lacking political will for a necessary change? 
Finding further challenges for the paradigm shift requires us to unpack assumptions about actants and processes in diverse organizational networks responsible for future-making. Here, we cannot limit ourselves only to the usual focus on transport planners as civil servants. We need to expand our focus to include other actants in the wider planning and innovation realm, especially since in this historical moment we have an unfolding of a significant amount of a diverse set of technologies and services in urban transport worldwide. Having in mind these people, the 20th century paradigm assumes that their role in future-making is one of experts and analysts, who should be objective and value free. Furthermore, the purpose of future-making is problem-solving and optimization, often framed as finding the best solution for a fixed and known set of ends, while also knowing beforehand all constraints. Hand in hand with this assumption, any future-making process should be a sequence of linear and logical steps, with some feedback loops, where facts and values can be addressed separately. Thus, in these processes, analysis and decision-making are separate, and problems can be defined in the absence of solutions. Ultimately, our organizational processes are mainly about predicting all the future problems, finding all the relevant alternatives, predicting the future status of the world, estimating outcomes, defining preferences for all outcomes, and effectively communicating with - or, some would say, educating - the decision-makers in our modern democracies.

An essential challenge to how we understand these human organizations and processes behind the much-needed transformation of our cities stems from the deep uncertainty of our lifeworld. The state of irreducibly high uncertainty creates huge difficulties for any attempts to define and predict the consequences of our actions in the present. Thus, we are facing self-reinforcing uncertainty, where we cannot know the future states of the world, and thus cannot predict and provide (Lyons and Davidson, 2016). This uncertainty should not be confused with our lack of data or of more advanced models. So, we are not just talking about content uncertainty, such as availability of information on time or contested knowledge in modern pluralistic societies with diverse social relations (Mouffe, 2000). Quite the contrary, this is an irreducible uncertainty of human existence, and is in fact plural: uncertainties. We can identify at least two more types, one being strategic uncertainty, such as challenges in articulating problems, anticipating actor responses, interactions and interests; and the other being institutional uncertainty, as we have processes with many actants with different institutional backgrounds stemming from often divergent institutional regimes and informalities (Koppenjan and Klijn, 2004).

Given the contested, complex and ambiguous nature of our lifeworld, how are we supposed to 'muddle through' (Lindblom, 1959) when making decisions about the future? Here, it is certainly obvious that future-making, especially underlined by diversity of values, requires advanced democratic 
institutions and processes. Future-making - and city-making - is thus not a technocratic but rather a political process, and a practice of knowing and acting. Given the above-mentioned uncertainties, future-making as the process of context-specific knowing thus includes several knowledge dimensions, as knowing what (cognitive/theoretical knowledge), knowing how (skills/technical knowledge), knowing to what end (moral choices) and doing (action/practice) (Davoudi, 2015). This situated knowing is provisional in the sense that it is constructed and constantly changing in a context which itself is constantly developing, where diverse actants have a varying capacity for knowing. These different capacities for knowing ultimately lead to challenges at the level of a single individual learner and knowledge integration, exposing previously hidden interrelatedness of (un)known factors.

Taking the idea of situated knowledge integration further through a processual perspective, we can find many parallels between many different fields reflecting on future-making, from urban planning to responsible innovation (Stilgoe et al., 2013). A similar set of principles emerges across these disciplines, which do not agree with the aforementioned predict-and-provide paradigm from the 20th century. Moving beyond the simplistic top-down towards more open-system processes, we should: (1) anticipate; (2) reflect; (3) deliberate; and (4) organize. This process assumption involves a higher degree of collective imagination about futures beyond path dependence, unpacking our assumptions and dilemmas, recognizing unknown unknowns, co-constructing and deliberating about (un)desirable visions, and understanding missing actants or relations between them, with associated roles and responsibilities in dynamic future-making networks.

As already mentioned, all this knowing and acting does not only happen at the level of individual actants, from offices of public administration in Lapland to coders in Silicon Valley. All the knowing and acting is both distributed and collective, requiring individuals to learn, but also to share group understanding. In learning from others, new practices are transferred, recombined and learned as they are created, and often involve knowledge that cannot be transferred. In addition, knowing and acting is mediated and contested through various relations between humans and with technologies (Verbeek, 2011). Taking into account these strong and loose webs of diverse actants, transformation of our cities will have to go hand in hand with transformation of our multi-level networked institutions. This transformation of our networks will require an understanding of their multiple ways of (un)learning over time (Albrechts et al., 2019; Baum, 1999). Such intra- and interorganizational (un)learning over time will have to recognize and embrace the human scale of these institutions themselves, recognizing unavoidable socio-emotional aspects (Mladenović and Eräranta, 2020). Ultimately, just as in our cities, socio-cultural structures within organizations are all too often in non-integrated silos. Such structures 
provide templates for the actant's experience, behaviour and identity, and are in turn shaped by the actant's activities over time.

\section{PERVASIVENESS OF HUMAN SCALE IN OUR CITIES AND ORGANIZATIONS}

Our reflection so far has taken us to recognize that we need to move away from the narrowly defined rationalist perspective on people on the move in the city, and people within organizations responsible for crafting futures of cities. Instead, we need to recognize the dynamically complex nature of people both in cities and in organizations. Anywhere we look into our modern systems, human scale seems inevitable. Perhaps embracing this pervasiveness of human scale seems inevitable. Perhaps the preservation of the status quo seems irresponsible. For example, we cannot pretend there are some 'average' humans in our cities, whose primarily commuting needs in the morning and return from work are all we need to care about. Similarly, we cannot pretend there are 'average' organizations and processes responsible for crafting urban futures. Either way, such assumptions will keep on locking us into the fundamentally unjust state that our systems recreate.

To unpack the multidimensional challenge for sustainability transformation, we need to further underline the potential in the concept of human scale cities. Similar terms such as 'liveable city', 'inclusive city', 'convivial city', and others have been emerging in recent years across policy and research documents. They are in themselves a proof of a need for paradigm change, as the 20th century paradigm is proving ineffective to deal with a multitude of present challenges. For this reason, the concept of human scale is an essential inspiration for a perspective shift in (un)learning in modern transport organizations. In addition, human scale is a foundation for a robust understanding of present problems and barriers to change. As such, human scale can be a guiding principle in context-dependent situations for nurturing the wide range of cities around the world, by opening the windows of opportunity for challenging the obsolete 20th century approach. With all this in mind, it seems that we still have something to learn from Socrates and his message from more than two millennia ago. Rescaling our focus towards human communities in cities can be a turning point for us collectively making cities and transport systems better for all life on this planet. How we integrate different kinds of knowledge-action aspects is something that is underpinning the 21 st century endeavour, and an underlying motivation for any piece of writing. 


\section{THE SCOPE OF THIS BOOK AS A CONTRIBUTION TOWARDS HUMAN SCALE CITIES}

This is the ninth book in the Network on European Communications and Transport Activities Research (NECTAR) Series on Transportation and Communications Networks Research, and stems from the contributions to the 2019 NECTAR conference organized in Helsinki, Finland. The theme of the conference, and thus the theme of this book, was 'Towards Human Scale Cities - Open and Happy'. Despite the fact that the chapters were mostly written before the COVID-19 pandemic, lessons for this and future times when deep uncertainties surface can be found across the chapters.

The book itself is organized into five parts, and all contributed chapters have been peer reviewed. Part II of this book includes six chapters, and aims to further expand our understanding of the human scale in the urban transport systems. Chapter 2 presents a critical analysis of relationships between transport and wellbeing. Chapter 3 explores a relationship between the distribution of the walkable qualities across different socio-economic groups, considering the distance to the city centre where most of the facilities are concentrated, through a case of Lisbon, Portugal. Chapter 4 assesses the relationship between accessibility, mode choice and income in Recife, Brazil. Chapter 5 focuses analysis on the difference that public transport subsidies make to workers' quality of life, using the case of Vancouver, Canada. Chapter 6 aims to understand challenges and motivators for walking and public transport use among the elderly, with insights from Porto and Lisbon, Portugal. Similarly, with a focus on mobility of elderly, Chapter 7 focuses on the needs and preferences related to car sharing in Oslo, Norway.

Part III of the book includes four chapters, further outlining the lessons for responsible innovation practices in mobility systems if we are to advance the human scale mobility technologies. Chapter 8 provides lessons for using stated adaptation experiments to understand the intended mode choice change in relation to the emerging Mobility-as-a-Service concept. Chapter 9 overviews the lessons from an automated bus deployment on a public road in Stockholm, Sweden. Next, Chapter 10 focuses on implications for behavioural change from monthly cycling challenges by using a smartphone application. The last chapter in Part III, Chapter 11, examines expert perspectives in Germany on neighbourhood-level integration of mobility measures and services.

Part IV includes seven chapters, elaborating on lessons for developing urban and transport planning processes, taking into account new data, methods and approaches. Chapter 12 provides a set of heuristics for repurposing street networks away from sole focus on private car use, using bicycles as proxies for human-scaled vehicles. Chapter 13 presents a case study of a planning 
support system aimed at areas with potential for cycling investments in starter cycling cities, applied to Matosinhos, Portugal. Chapter 14 compares a range of common qualitative and quantitative data sources for conducting cycling studies worldwide. Next, Chapter 15 presents a performance analysis of factors associated with citizens' sensing from case studies in the Netherlands. Chapter 16 reviews experiences from transport planning projects in the United States, United Kingdom, Finland, the Netherlands, Australia and New Zealand which have implemented public participation geographic information system (GIS) methodology. Chapter 17 analyses the application of Multi-Actor Multi-Criteria Analysis for participatory evaluation of co-designed solutions to transport problems in Brussels, Belgium. The last chapter of Part IV, Chapter 18, is a case study analysis of metro planning and implementation in Lima, Peru. Finally, the book ends with Part V, which in Chapter 19 provides a summarized set of findings and selected points for action from the whole book, thus serving as its conclusion.

As any piece of literature, the book also had to leave certain aspects out of its scope. Overall, the book mostly focuses on lessons from medium- and high-income countries, showing that transformation even in these places is not as straightforward as one could assume, given the resources available. Nonetheless, some lessons could be drawn indirectly for low-income countries, if they are to avoid and leapfrog over the unsustainable path dependencies associated with the petroleum-fuelled car-dependent societies. Ultimately, we hope that this book will be another swing at the cracking 20th century paradigm, and a gust of wind in the sails of the emerging, and much needed, human scale one - the one suitable for the challenges of the 21 st century.

The book is considered to be useful for a range of policy-makers, practitioners, as well as citizen advocates, as they would find a range of compelling arguments for broadening the discussion on understanding humans in the city, and necessary actions for the transition out of the current unsustainable regime. In addition, educators and graduate students could use parts of this book, especially from Parts I and III, as general reading material in (transport) planning and policy courses. Finally, researchers would find plenty of inspiration for exploring new research and action directions across specific chapters, and as summarized in the concluding Part V.

\section{REFERENCES}

Albrechts, L., Barbanente, A., and Monno, V. (2019). From stage-managed planning towards a more imaginative and inclusive strategic spatial planning. Environment and Planning C: Politics and Space, 37(8), 1489-1506.

Banister, D. (2008). The sustainable mobility paradigm. Transport Policy, 15(2), 73-80. 
Baum, H. (1999). Forgetting to plan. Journal of Planning Education and Research, 19(1), 2-14.

Berlin, I. (1969 [2000]). Four essays on liberty. In J.J. Schwarzmantel and R. Blaug (eds), Democracy: A Reader (pp. 113-116). New York: Columbia University Press.

Bertolini, L. (2017). Planning the Mobile Metropolis: Transport for People, Places and the Planet. London: Macmillan International Higher Education.

Cairns, S., Harmer, C., Hopkin, J., and Skippon, S. (2014). Sociological perspectives on travel and mobilities: A review. Transportation Research Part A: Policy and Practice, 63, 107-117.

Davoudi, S. (2015). Planning as practice of knowing. Planning Theory, 14(3), 316-331. de Roo, G., and Silva, E.A. (eds) (2010). A Planner's Encounter with Complexity. Aldershot: Ashgate.

De Vos, J. (2019). Satisfaction-induced travel behaviour. Transportation Research Part F: Traffic Psychology and Behaviour, 63, 120-21.

Geels, F.W., Sovacool, B.K., Schwanen, T., and Sorrell, S. (2017). Sociotechnical transitions for deep decarbonization. Science, 357(6357), 1242-1244.

Geurs, K., and Macharis, C. (2019). The future of European communication and transportation research: a research agenda. Region, 6(3), D1-D21.

International Panel on Climate Change (IPCC) (2019). Global Warming of $1.5^{\circ} \mathrm{C}$. An IPCC Special Report on the impacts of global warming of $1.5^{\circ} \mathrm{C}$ above pre-industrial levels and related global greenhouse gas emission pathways, in the context of strengthening the global response to the threat of climate change, sustainable development, and efforts to eradicate poverty. [Masson-Delmotte, V., P. Zhai, H.-O. Pörtner, D. Roberts, J. Skea, et al. (eds)]. Retrieved from https://www.ipcc.ch/sr15/ download/.

Jensen, O.B. (2009). Flows of meaning, cultures of movements-urban mobility as meaningful everyday life practice. Mobilities, 4(1), 139-158.

Koetse, M.J., and Rietveld, P. (2012). Adaptation to climate change in the transport sector. Transport Reviews, 32(3), 267-286.

Koppenjan, J., and Klijn, E.H. (2004). Managing Uncertainties in Networks: A Network Approach to Problem Solving and Decision Making. New York: Psychology Press.

Lindblom, C.E. (1959). The science of 'muddling through'. Public Administration Review, 19(2), 79-88.

Lucas, K., Mattioli, G., Verlinghieri, E., and Guzman, A. (2016). Transport poverty and its adverse social consequences. Proceedings of the Institution of Civil Engineers Transport, 169(6), 353-365.

Lyons, G., and Davidson, C. (2016). Guidance for transport planning and policymaking in the face of an uncertain future. Transportation Research Part A: Policy and Practice, 88, 104-116.

Mladenović, M.N., and Eräranta, S. (2020). Hear the Rime of the Fellow Mariner? A letter to the next generation of emphatic co-creators in planning. Planning Theory and Practice, 21(1), 164-174.

Mladenović, M.N., Lehtinen, S., Soh, E., and Martens, K. (2019). Emerging urban mobility technologies through the lens of everyday urban aesthetics: case of self-driving vehicle. Essays in Philosophy, 20(2), 146-170.

Mouffe, C. (2000). The Democratic Paradox. London: Verso Books.

Nasar, J.L. (ed.) (1988). Environmental Aesthetics: Theory, Research, and Application. New York: Cambridge University Press.

Rawls, J.A. (1971). A Theory of Justice. Cambridge, MA: Harvard University Press. 
Raworth, K. (2012). A safe and just space for humanity: can we live within the doughnut? Oxfam Policy and Practice: Climate Change and Resilience, 8(1), 1-26.

Sheller, M. (2018). Mobility Justice: The Politics of Movement in an Age of Extremes. London: Verso

Simon, H.A. (1990). Bounded rationality. In J. Eatwell, M. Milgate and P. Newman (eds), Utility and Probability (pp. 15-18). London: Palgrave Macmillan.

Stilgoe, J., Owen, R., and Macnaghten, P. (2013). Developing a framework for responsible innovation. Research Policy, 42(9), 1568-1580.

Urry, J. (2004). The 'system' of automobility. Theory, Culture and Society, 21(4-5), $25-39$.

Van Geenhuizen, M., and Nijkamp, P. (2003). Coping with uncertainty: an expedition into the field of new transport technology. Transportation Planning and Technology, 26(6), 449-467.

Verbeek, P.P. (2011). Moralizing Technology: Understanding and Designing the Morality of Things. Chicago, IL: University of Chicago Press.

World Health Organization (WHO) (2018). Global Status Report on Road Safety 2018. Geneva: World Health Organization. 